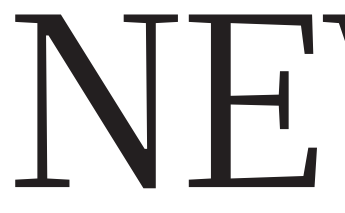

BIOMEDICINE Huge funding revamp stuns Canadian researchers $\mathbf{p . 2 7 2}$
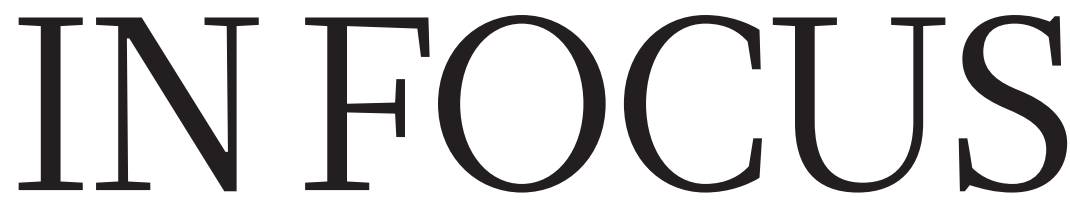

IRAN Collaboration and a new lab beckon if nuclear deal holds $\mathbf{p . 2 7 4}$
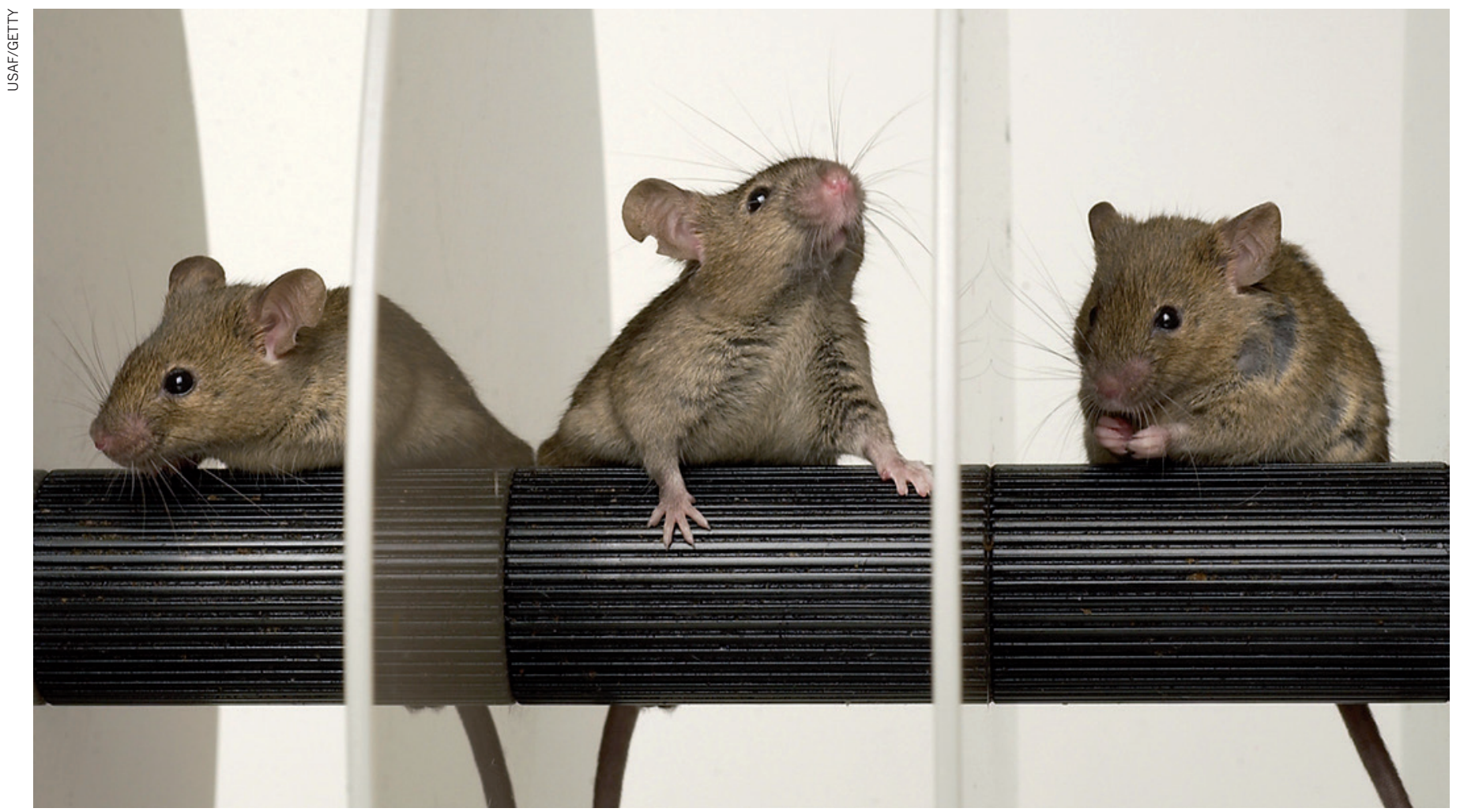

Experiments that use only a small number of animals are common, but might not give meaningful results.

\title{
MEDICAL RESEARCH
}

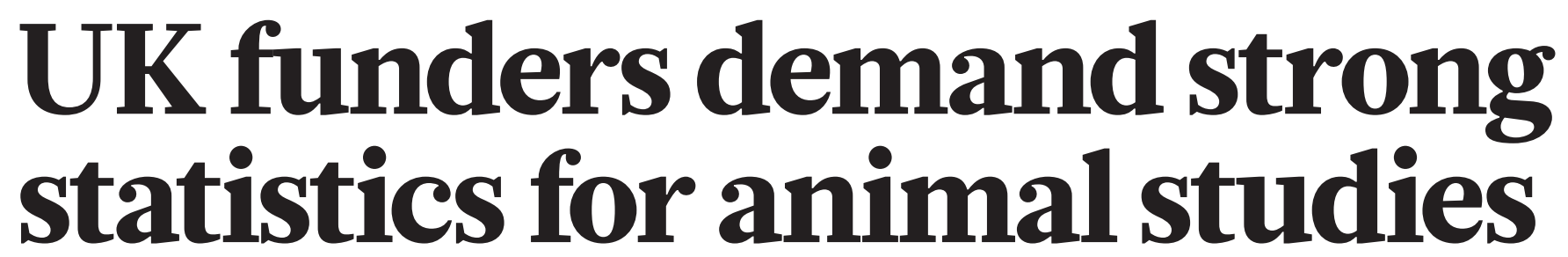

\section{Move addresses concerns that some experiments are not using enough animals.}

\section{BY DANIEL CRESSEY}

$\mathrm{R}$ eplace, refine, reduce: the 3 Rs of ethical animal research are widely accepted - around the world. But now the message from UK funding agencies is that some experiments use too few animals, a problem that leads to wastage and low-quality results.

On 15 April, the research councils responsible for channelling government funding to scientists, and their umbrella group Research Councils UK, announced changes to their guidelines for animal experiments. Funding applicants must now show that their work will provide statistically robust results - not just explain how it is justified and set out the ethical implications or risk having their grant application rejected.

The move aims to improve the quality of medical research, and will help to address widespread concerns that animals - mostly mice and rats - are being squandered in tiny studies that lack statistical power.

"If the study is underpowered your results are not going to be reliable," says Nathalie Percie du
Sert, who works on experimental design at the National Centre for the Replacement, Refinement and Reduction (NC3Rs) of Animals in Research in London. "These animals are going to be wasted."

Researchers say that sample size is sometimes decided through historical precedent rather than solid statistics. There is also a lack of clarity: last year, an analysis of selected papers published in Nature or Public Library of Science journals describing animal experiments revealed that few reported the use of statistical tests to 
ANIMAL USE $\mid \ln 2013$, fundamental biology accounted for most animal experiments in the United Kingdom.

\begin{tabular}{llrr|}
\hline & & & \\
2 MILLION PROCEDURES* & & Veterinary \\
Fundamental & Human medicine & medicine & Other \\
biological research & or dentistry & $8 \%$ & $3 \%$ \\
$\mathbf{5 8 \%}$ & $26 \%$ & $3 \%$ \\
& & \\
\end{tabular}

Toxicological and related evaluations

*Breeding procedures such as genetic modification not included.
- determine sample size, even though both publishing groups had endorsed guidelines to improve reporting standards (D. Baker et al. PLoS Biol. 12, e1001756; 2014).

Animals feature in a wide range of experiments (see 'Animal use'), many of which are designed to test drugs before trials are done in people. The effects that researchers are looking for in these preclinical studies are often subtle, and 'power calculations' are needed to reveal the number of animals needed to show an effect. But an international academic partnership called the CAMARADES project (Collaborative Approach to Meta Analysis and Review of Animal Data from Experimental Studies), has shown that many animal studies are underpowered: studies in stroke, for example, are typically powered at between $30 \%$ and $50 \%$, meaning that there is just a $30-50 \%$ chance of detecting a biological effect if it exists.

Malcolm Macleod, a neuroscientist at the University of Edinburgh, UK, blames, among other things, a lack of training and support in experimental design, as well as limited funds: animals are expensive to work with.

Some say that the pressure to 'reduce' may be one of the reasons for small experiments, but others counter that this is a misinterpretation of the 3 Rs because small experiments are ethically problematic if they have low statistical power.

The problem is not limited to Britain: last year, Francis Collins, director of the US National Institutes of Health (NIH), and Lawrence Tabak, NIH deputy director, warned about a lack of reproducibility in preclinical research and mentioned a dearth of sample-size calculations as one of the problems (see Nature 505, 612-613 2014).

The situation infuriates animal-welfare proponents. "It's completely unethical to use animals in studies that aren't properly designed," says Penny Hawkins, head of the research-animals department at the Royal Society for the Prevention of Cruelty to Animals in Southwater, UK.

Boosting the number of animals in specific experiments need not mean more animals are used overall because multiple small experiments can often be replaced by fewer, larger ones "One potential implication is we need to ask for money to do larger studies," says Marcus Munafò, a psychologist at the University of Bristol, UK.

Another way to increase sample sizes would be to link up researchers working on similar topics. Munafò notes that this is what geneticists now do for studies that require scanning a large number of genomes. "That template already exists," he says. "The question is, how do you initiate that cultural change?"

More immediately, du Sert is developing an online tool for the NC3Rs that will help researchers to design robust studies. "We're not blaming anyone for the way they were doing things before," she adds. "That was the practice at the time." - SEE EDITORIALP.263

\section{Canadians baulk at reforms to health-research agency}

\section{Biomedical-funding revamp threatens to marginalize under-represented researchers.}

\section{BY SARA REARDON}

$\mathrm{T}$ he biggest overhaul in the 15-year history of the Canadian Institutes of Health Research (CIHR) was meant to rescue biomedical researchers from the endless grant applications and Byzantine peer-review processes that had become a feature of the cash-strapped agency. "The research community was complaining bitterly," says Alain Beaudet, president of the CIHR in Ottawa. "They begged me to make changes."

But now that reality is kicking in, many researchers worry that the changes - which modify how grants are awarded, restructure advisory boards and reallocate the money funnelled through the 13 virtual institutes that comprise the CIHR — will marginalize some fields and hurt early-career researchers.

Beaudet says that the plans have been in place for some time, but many researchers - particularly those on the institutes' scientific advisory boards - complain that the CIHR has failed to communicate the changes adequately, and that the number of simultaneous reforms is overwhelming.

"We're a little bit stunned," says Gillian Einstein, a cognitive neuroscientist at the University of Toronto and chair of the board that advises the CIHR's Institute of Gender Health. "I'm not sure the groundwork was laid so we'd understand what was happening."

Each institute has its own advisory board with up to 12 members, and receives a dedicated allotment of about Can $\$ 8.5$ million (US\$6.7 million) from the CIHR's Can\$1-billion annual research budget. In the 2016 budget, these outlays will be cut in half, with the savings going into a common fund. To access this new funding source, institutes will have to work together to design cross-disciplinary initiatives that have extra support from a funding partner such as a charity, institution or company. Beaudet says that the CIHR will be responsible for finding many of these partners.

The CIHR also plans to eliminate most of the scientific advisory boards, leaving only three or four panels, which will advise several institutes each. An internal panel is still evaluating the plan, which would not take effect before April 2016. Nearly all of the advisory boards are protesting the changes. "If you're doing well and have some vision, and someone took half your toolset away, I'd say the rug was pulled out," says Anthony Jevnikar, a nephrologist at Western University in London, Ontario, who chairs the advisory board for the Institute of Infection and Immunity.

\section{BAR TO ENTRY}

Feathers are also being ruffled by changes to the CIHR's system for awarding grants to proposals submitted by researchers. In July, 